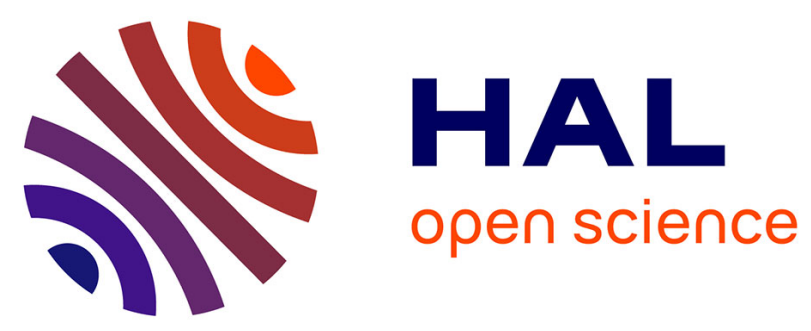

\title{
The Role of Additive Manufacturing in the B2C Value Chain: Challenges, Opportunities and Models
} Vittorio Zanetti, Sergio Cavalieri, Matteo Kalchschmidt, Roberto Pinto

\section{To cite this version:}

Vittorio Zanetti, Sergio Cavalieri, Matteo Kalchschmidt, Roberto Pinto. The Role of Additive Manufacturing in the B2C Value Chain: Challenges, Opportunities and Models. IFIP International Conference on Advances in Production Management Systems (APMS), Sep 2015, Tokyo, Japan. pp.137-145, 10.1007/978-3-319-22759-7_16. hal-01431087

\section{HAL Id: hal-01431087 \\ https://hal.inria.fr/hal-01431087}

Submitted on 10 Jan 2017

HAL is a multi-disciplinary open access archive for the deposit and dissemination of scientific research documents, whether they are published or not. The documents may come from teaching and research institutions in France or abroad, or from public or private research centers.
L'archive ouverte pluridisciplinaire HAL, est destinée au dépôt et à la diffusion de documents scientifiques de niveau recherche, publiés ou non, émanant des établissements d'enseignement et de recherche français ou étrangers, des laboratoires publics ou privés. 


\title{
The role of Additive Manufacturing in the B2C Value Chain: challenges, opportunities and models
}

\author{
Vittorio Zanetti, Sergio Cavalieri, Matteo Kalchschmidt, Roberto Pinto \\ University of Bergamo, Department of Management, Information and Production Engineering \\ Viale Marconi. 5 - 24044 Dalmine (BG) - Italy \\ v.zanetti@studenti.unibg.it, sergio.cavalieri@unibg.it, \\ matteo.kalchschmidteunibg.it, roberto.pinto@unibg.it
}

\begin{abstract}
Additive manufacturing is shifting business models towards mass customisation and responsible production paradigms. Such a technology is fostering re-localisation and value-added approaches in order to increase customer involvement into a more flexible and sustainable production process. This paper provides both theoretical tools and case studies to frame the additive manufacturing realm and the distributed fabrication background.
\end{abstract}

Keywords: Additive Manufacturing, Value Chain, Business Model, Sustainability, Glocalization, Distributed Manufacturing, Co-production.

\section{$1 \quad$ Introduction}

During the last 20 years, the manufacturing world has been undergoing some disruptive innovations that have changed the way production is conceived. A shift toward its intangible side has been driven by both digitalisation and servitisation. Overcoming the traditional distinction between labour and capital-intensiveness, many businesses can be termed as data-intensive, since several steps along their value chain rely on ICT and digitalised resources in order to provide better responsiveness and cost-effectiveness.

To face with the more stringent market requirements, traditional production approaches based on make-to-order transactional strategies have to cope with mass-production principles and an intimate relationship with the customer. This means managing small and diversified batches [1] and giving rise to a "make-to-individual" relational-based paradigm with an increase of management complexity and, therefore, a potential upsurge of production and service provision costs and risks. Service-driven processes, such as design, support and maintenance, are now crucial to the customer, and can ensure a competitive advantage for enterprises, regardless of their dimension.

The combination of these trends is pushing companies to rethink their value creation mechanisms by changing from a global to a local perspective - from a standardization to a customization approach - and therefore becoming a "good and reliable neighbor" for the final customer [2]. A glocal strategy is supposed to find the right balance between a global approach (typically related to efficiency) and a local perspective (related to responsiveness) [3]. 
Firms with global brands and technologies are now considering to meet local customisation needs and to endorse nearby resources and expertise. They shift "from primary producers and distributors to aggregators" [4] to coordinate a network of trade and commerce across the value chain, playing the role of logistic orchestrators, decentralising their operations and digitalizing their structures. While raw materials and data flow into a global network, skills and production sites can be managed by proximity, thereby reducing the complexity typically related to the scale [5]. Factories have to be conceived as modular, easily reconfigurable, adaptive and evolving, capable of small scale production to create new customized products and services, environmental friendly and able to respond to the continuous change of the market [6].

To tackle all these challenges and maintain the competitive leadership in different markets, technology can play an important enabling and boosting role in developing value by providing innovative ideas to be turned into new customer-oriented production systems allowing also to balance uncertainty along the supply chain [7].

In such a context, this paper addresses specifically the role of Additive Manufacturing (AM) as a key enabling technology for the dynamic reconfiguration of "customer-oriented value" constellations of manufacturing companies and solution providers, capable to operate at multiple locations in proximity with the customer. Through the description of relevant case studies, the paper provides a descriptive framework, which identifies different structures of value chains according to the combination and consistency of strategic, managerial and operational dimensions.

\section{Value chain reconfiguration: the case of additive manufacturing}

To properly drive the manufacturing change, firms should consider what is more valuable for their customers and partners. Cost-cutting is no longer the main concern in creating value. Moreover, digitalisation is changing the rules of the game such that it soon may allow customisation with negligible costs [8]. The Shih's "Smile Curve"[9] (Figure 1a) helps in understanding the shift of the contribution to the added value coming from different value-chain stages: while in the past, pre-production (R\&D, design, subcontracting) and post-production (logistics, marketing, aftersales) stages were slightly more important than production (manufacturing, assembly) itself, nowadays upstream and downstream stages are becoming crucial to the value chain. Co-designing the product with the customer or providing availability contracts and maintenance can really generate the willingness to pay for a premium price.

To build such commendable value chains, enabling technologies are required, like for instance Additive Manufacturing. AM, often referred to as 3D-printing, is a manufacturing process operating through deposition of material layer by layer onto a substrate; such a process enables the creation of complex structures starting from a 3-D CAD model, without the additional costs that traditional subtractive technologies usually require (Figure 1b). More importantly, design complexity is often correlated to flexibility, customisation and energy efficiency.

An AM-based process can use different materials and deposition techniques, and is particularly suitable for small series and personalised products manufacturing, spare parts and prototyping. The latter was noticeably the first application of such technology dating back in the 1980s, when AM was still named "Rapid Prototyping". Today, AM is widely used in aerospace, defense, automotive, healthcare, consumer products and retail. 


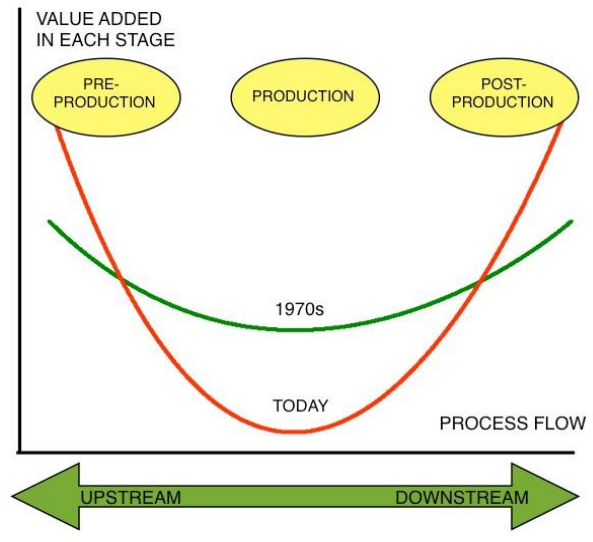

Fig. 1. (a) The Value Chain Smile Curve

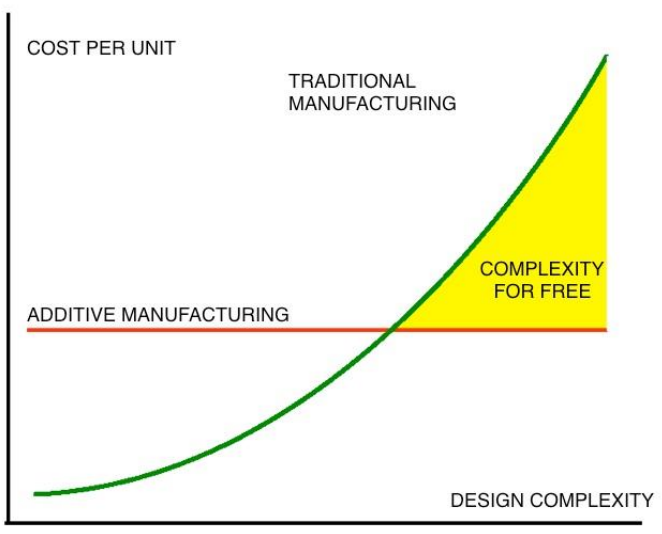

(b) Cost of design complexity

Since with AM labour is no longer a critical source, the advantage of locating production in countries where its cost is lower will be eroded soon, fostering re-localisation and customer proximity. Moreover, since products could travel along the value chain mostly as digitally stored data, thereby tearing down the wall between production and delivery, the sustainability trait of AM (summarised in Table 1) is starting to threaten traditional subtractive techniques.

Table 1. Sustainability traits of Additive Manufacturing

\begin{tabular}{|c|c|c|}
\hline $\begin{array}{c}\text { Economic } \\
\text { sustainability }\end{array}$ & $\begin{array}{c}\text { Social } \\
\text { Sustainability }\end{array}$ & $\begin{array}{c}\text { Environmental } \\
\text { sustainability }\end{array}$ \\
\hline Flexibility & Democratization & Waste reduction \\
\hline Lower Time to Market & Local expertise endorsement & Energy efficiency \\
\hline Complexity for free & Regional availability & Customer proximity \\
\hline Lower production costs & Customer involvement & Digital movement \\
\hline
\end{tabular}

\section{Additive manufacturing-driven value networks}

In order to ensure a successful implementation of AM, proper configurations of value networks must be identified. In this section, three Business-to-Consumer scenarios are presented: Home, Distributed and Centralised Printing. The following models, represented in Figure 2, are drawn and adapted from previous literature $[10,11,12]$ without any claim to completeness.

In the Home Printing Scenario, the customer sends a request to a service provider that supplies her with a 3D-printable CAD model. Alternatively, in the "Maker" case, the customer is also a designer and does not need the service provision of a third party to print her creations. This scenario is unlikely to scale up in the short term, since makers and enthusiasts are just a small niche of the market. According to many scholars, the "Desktop Manufacturing" requires design skills that normal customers are unwilling to develop or unlikely to learn.

In the Distributed Printing Scenario, the customer sends the products specifications to an aggregation platform that outsources local 3D printing retailers (typically, but not necessarily, the 
printer owners) who can ship the finished product to the customers after printing it. This model can be declined in many ways and relevant cases are further discussed.

In the Centralised Printing Scenario, the printing stage is "behind the scenes" and does not affect the configuration of the logistic chain, since the impact is solely on the production process. In this model, the environmental concern trait is weakened, thus making it unlikely to be adopted in re-localisation contexts.

It is not in the purpose of the paper to show exhaustively the differences between the aforementioned models, but instead providing real cases for the Distributed Printing Scenario, where $\mathrm{AM}$ is the major (but not the only) enabler for a decentralised fabrication paradigm. Four noteworthy models are presented below and summarised in Figure 2c.

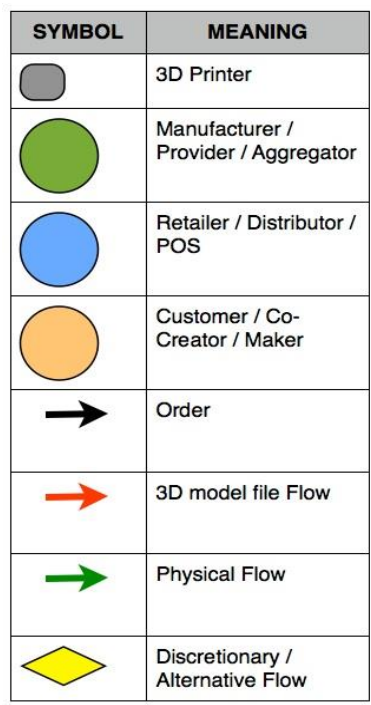

Fig. 2. (a) Legend

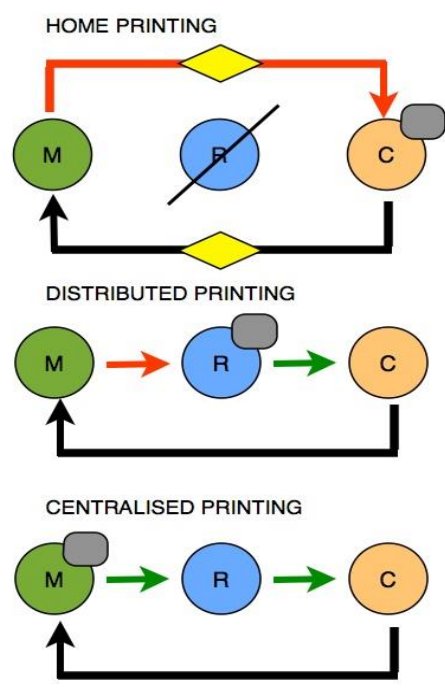

(b) Scenarios
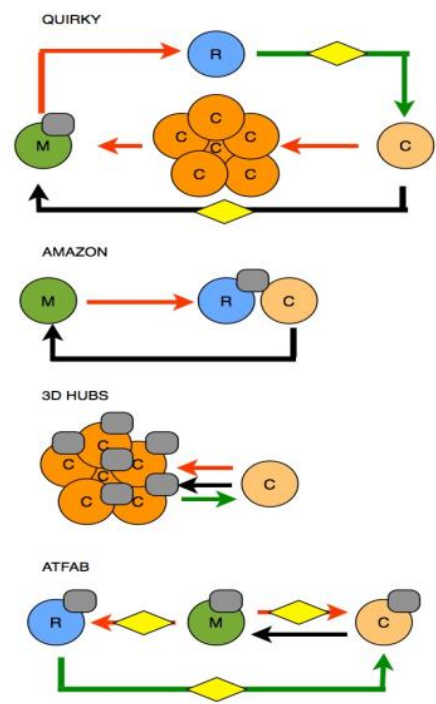

(c) Case studies

\subsection{Crowdsourcing and collaborative platforms: Quirky}

With the rise of the digitalisation and social networks, end users have started to go beyond the consumption status and become more and more involved in the production world. More specifically, innovation is now within the range of everyone thanks to the so-called crowdsourcing platforms. The name stresses both participation and engagement that people can show in new product and service development, simply by submitting ideas, evaluating proposals and finding suppliers and partners for something, which is not yet in the state of the art [13]. Even larger businesses are turning to crowdsourcing instead of relying on internal R\&D [14]. With Quirky [15] for instance, anyone can be a designer and submit her idea, which is evaluated and even improved by the community and, if successful, manufactured by internal experts and sold in retailing shops. Needless to say, the manufacturing stage can be performed by AM machines that disclose com- 
plex designs and allow performance-based continuous adjustment - based on community feedbacks - at low costs. Note that Quirky manages all the product supply chain and IPR, which is no longer in the hands of the creator as soon as she decides to submit her idea.

\subsection{En Route Fabrication and Localised Manufacturing: Amazon 3D-Printing Trucks}

As mentioned before, AM makes the discrimination between production, delivery and consumption quite subtle and fuzzy, and new localised manufacturing models are arising in the light of cost-effectiveness. While UPS is expanding its 3D printing in-store services in collaboration with Stratasys [16], a world-class leader in the AM realm, Amazon is thinking outside the box [17]. As a matter of fact, the company has recently filed a patent application about a business model where the printing stage is performed in travelling trucks. The customer submits the order and the nearest truck starts its route, producing the goods en route. This model can be purposeful for B2B contexts too, where spare parts availability is a major concern. Thanks to this configuration, where the glocal trait is undeniable, trucks will soon carry solely raw materials on board and become fabrication "movable" points with both additive and subtractive technologies equipment. The intrinsic risk of such a patent is the robustness of the production process. Interesting enough, while the world of manufacturing is experiencing servitisation, the world of retailing is approaching what can be defined "productisation": AM technology turns out to be so disruptive that two previously sequential steps are now becoming overlapped.

\subsection{Sharing Economy and Community Crafting: 3D Hubs}

Recently the tags "B2B" and "B2C" have become unsatisfactory in labelling business models comprehensively: as a matter of fact, a new paradigm defined " $\mathrm{C} 2 \mathrm{C}$ " (i.e. Customer to Customer), often referred as to peer-to-peer or sharing economy, has changed the business rules [18]. Completely compliant with the servitisation trend and "post-scarcity" economy, customers are no longer interested in owning an asset, but rather in using it for a certain amount of time by paying a predetermined fee. A noteworthy example is 3D Hubs [19], a community made of printer-owners and users who meet both physically and in a virtual marketplace. The customer orders a product or uploads her design through a marketplace and chooses the closest printer owner - typically within $10 \mathrm{~km}$ - willing to provide the service. 3D hubs then charge the user with a $15 \%$ commission on the final price set by the service provider, who can even be a user of the marketplace at the same time. According to [19], the hub is now made of more than fourteen thousand peers worldwide with a 3D printer. 3D Hubs does not only provide an on-demand customisable service, but also creates a community of enthusiasts and curious gravitating towards AM with a sustainable incentive mechanism: the users are willing to explore new design solutions at accessible prices, while the printer-owners are keen on shrinking the idle time of their equipment through its rental. The underlying issues are firstly preventing users to bypass the platform once they know each other to avoid the commission and secondly managing complaints.

\subsection{Co-configuration and Adaptive Factories: AtFab}

Another major trend driving the manufacturing revolution is the Open Source approach, where producers give away their IP to customers and encourage them to experiment or suggest 
improvements, thereby spurring a bottom-up empowerment. The customers take part to the configuration of a product by either producing it directly, deciding where and how it should be manufactured or just even editing a design provided by the supplier and outsourcing its production. The end user is no longer a mere co-designer but a co-configurator [20] arranging not just the product itself, but its production process, sourcing, delivery and reuse (disassembly). The case of AtFab [21], a design firm co-founded by two architects, is noteworthy in this regard, given its higher degree of adaptation with respect to customer needs. The customer is free to choose whether to edit online models and print them on her own, to choose the nearest fabrication point to make that for her, or even to order a finished product directly from the marketplace. Although AtFab is linked to subtractive manufacturing techniques, the $\mathrm{CNC}$ routers and milling machines are completely consistent with the supply chain digitalisation and disintermediation that AM is driving. The social challenges of such mechanism are finding designers/negotiators willing to give away their expertise and IP and ensuring that local fabrication centres are quality-compliant.

\section{$4 \quad$ A descriptive framework}

The previous cases can be framed into a comprehensive matrix, reported in Figure 3. On the bottom $\mathrm{x}$-axis we discern between product- and solution-based approaches, while on the top $\mathrm{x}$ axis a Wortmann-based taxonomy is proposed. On the left-hand y-axis we distinguish two different settings: one where there is a focal company delegating production to local factories, and the other where there is a peer-to-peer constellation of firms, based on sharing economy or feedbacks collection. On the right-hand y-axis we differentiate a customer-oriented (one to one) from a community oriented (many to many) outcome. Note that risk sharing increases going through the $\mathrm{x}$-axis, running parallel to the degree of intangibility in the value proposition and to the customer commitment required. Going down instead along the y-axis, a manufacturing democratisation trait emerges, as well as a bottom-up engagement.

The proposed matrix pinpoints four archetypes and their issues; it serves as a sense-making tool to structure and characterize the state of the art and to establish recurring principles, triggering factors and primary concerns. It provides clarity and can even guide implementation of pertaining initiatives and research.

- The Localised Manufacturing context, enabled by timely technology supported by end-to-end marketplaces, offers to customers real-time order traceability and high performances on the delivery, but requires a robust logistic optimisation.

- The Adaptive Factory is grounded on an open source mind-set and provides demanding customers with an extreme flexibility along the product life cycle, but requires suppliers who are willing to take part of a discretionary - or even opportunistic - relationship.

- In the Community Crafting circumstance, the "value proposition" is the recreational aspect of the transaction. Still, sharing economies and disintermediation initiatives encompass different issues related to quality, complaints, logistics and critical mass.

- Collaborative Platforms entangle crowdsourcing and community feedback systems, display basically no entry barriers and disclose user innovation. Sometimes the creator may experience a loss of IP or a long gestation before the actual implementation/ manufacturing of her idea that could even be far from the original submission. 


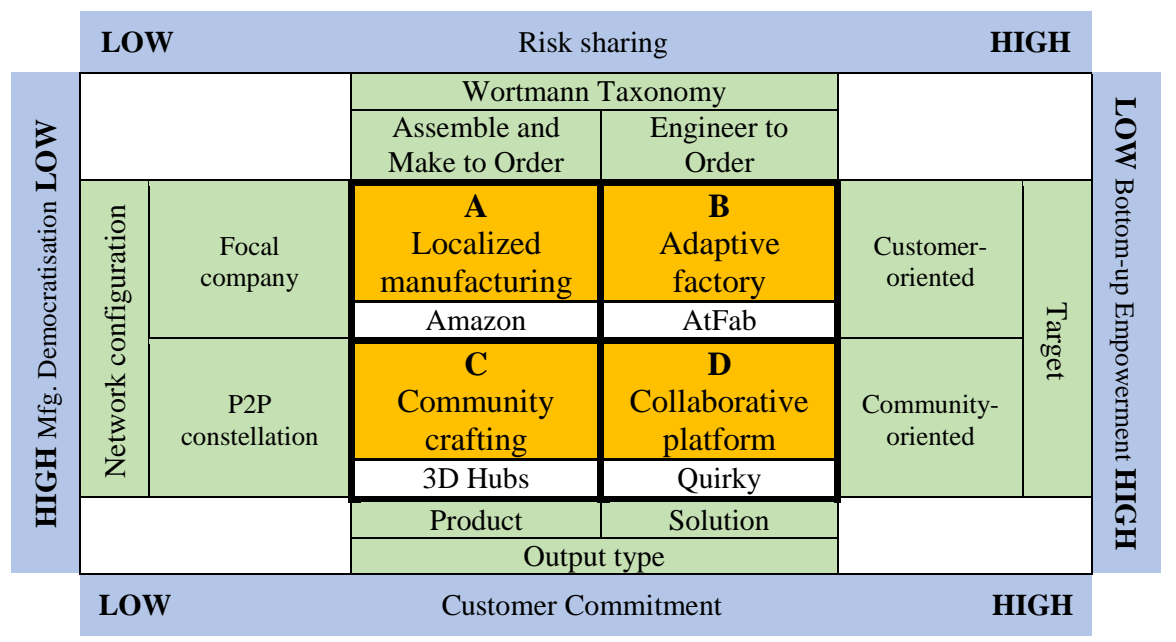

Fig. 3. The four-quadrant descriptive framework

\section{Conclusions}

Reluctance towards Additive Manufacturing is motivated by its constraints and yet unsolved issues (production time, volume, material, safety conditions, etc.). Those drawbacks will soon be ridden out and, most importantly, the social connotation of such technology - sometimes referred to as "democratisation of manufacturing" - will be recognized and endorsed.

Regardless of the value chain configuration, a thorough digitalisation of production processes is ongoing. Digital platforms manage order purchase and co-development, they enable partner contracting and an easier supplier selection problem, facilitate project planning and monitoring and even collect real-time feedbacks. The digital infrastructure underlying the manufacturing realm will facilitate both imitators and innovators to fast new product development through disruptive technologies such as 3D Printing. Still, this "digitalised" situation will be completely consistent with the endorsement of human expertise in designing high-performing goods: "the artisan production worker will return to prominence" [22]. AM seems to be the proper technology to overcome even the mass customisation and to devise new responsive and responsible models of production, distribution and consumption. Especially for high-value industries in which rapid innovation is much more crucial than cost efficiency, AM could access to highly skilled talents, more important than hourly labour rates in production location decision making. As afore mentioned, proximity to customer concurrently means value increase and sustainability opportunities.

This paper represents a first attempt to frame some relevant arising business models related to advanced manufacturing techniques. Strategic and operational issues related to demand volatility and result-oriented provisions are highlighted and discussed. Distributed manufacturing and servitisation are now endorsing re-localisation of businesses and re-integration of the customer in the value chain, outlining new sustainable and participatory models.

Further research is solicited to devise dialogical expertise and intuitive tools that can help customers, designers, producers, distributors and retailers devise the next industrial revolution. 


\section{References}

1. Boër, C. R. and Dulio, S.: Mass Customization and Footwear: Myth, Salvation or Reality? Springer Verlag London Limited, pp. 5-7 (2007).

2. Cavalieri, S., Romero, D., Strandhagen, J.O, Schönsleben, P.: Interactive Business Models to Deliver Product-Services to Global Markets. In APMS, IFIP Advances in Information and Communication Technology, Vol. 415, pp 186-193, Springer-Verlag Berlin Heidelberg (2013).

3. Svensson, G.: Glocalization of business activities: a glocal strategy approach, Management Decision, Vol, 39 Iss: 1, pp. 6-18 (2001).

4. Rifkin, J.: The Third Industrial Revolution: How Lateral Power Is Transforming Energy, the Economy, and the World. Palgrave Macmillan Trade (2012).

5. Manuj, I. and Mentzer, J. T.: Global supply chain risk management strategies. International Journal of Physical Distribution \& Logistics Management, Vol. 38, No. 3, pp. 192-233 (2008).

6. Selladurai, R. S.: Mass customization in operations management: oxymoron or reality?. The International Journal of Management Science, Omega Vol. 32, pp. 295-300 (2004),

7. Gualandris, J. and Kalchschmidt, M.: Product and process modularity: improving flexibility and reducing supplier failure risk, Int. Journal of Production Research, Vol. 51, 19, pp. 5757-5770 (2013).

8. Rifkin, J.: The Zero Marginal Cost Society: The Internet of Things, The Collaborative Commons, and the Eclipse of Capitalism. Palgrave Macmillan Trade (2014).

9. Jason, Kenneth L. Kraemer, and Tony Tsai: ACER: an IT Company Learning to Use Information Technology to Compete, Center for Research on Information Technology and Organization, University of California, Irvine October (1999).

10. Shipp, S., Gupta, N., Lal, B., Scott, J.A., Weber, C, Finnin, M.S., Blake, M., Newsome, S., Thomas, S. : Emerging Global Trends in Advanced Manufacturing:, Institute for Defense Analyses, P-4603 (2012).

11. Birtchnell, T., Urry, J., Cook, C. and Curry, A.: Freight Miles, The impacts of 3D Printing on Transport and Society, Economic \& Social Research Council (2012).

12. Rayna, T. and Striukova, L.: Impact of 3D Printing Technologies on Business Model Innovation, In: Digital Enterprise Design \& Management, Advances in Intelligent Systems and Computing Volume 261, Chapter 11, pp. 119-132 Springer Verlag (2014).

13. Estellés-Arolas, E. and Gonzaléz-Ladròn-de-Guevara, F.: Towards an integrated crowdsourcing definition, Journal of Information Science, Vol. 38, No. 2 pp.189-200 (2012).

14. Marsden, P.: Crowdsourcing: Your Recession-Proof Marketing Strategy?, Contagious 18 pp. 24-27, www.contagiousmagazine.com (2009).

15. Quirky Shop. www.quirky.com, last retrieved 15/4/2015

16. TCT Magazine: UPS Expands 3D Printing Service Across US. http://www.tctmagazine.com/3D-printing-news/ups-expands-3d-printing-service/ last retrieved 15/4/2015.

17. 3dPrint.com: Amazon Files Patent for Mobile 3D Printing Delivery Trucks, http://3dprint.com/46934/amazon-3d-printing-patent/, last retrieved 15/4/2015.

18. Rachordás, S.: Does Sharing Mean Caring? Regulating Innovation in the Sharing Economy, Tilburg Law School Legal Studies Research Paper Series No. 06/2015 (2015).

19. 3DHubs: https://www.3dhubs.com/, last retrieved 15/4/2015.

20. Victor, B. and Boynton, A.: Invented here: Maximizing your organization's internal growth and profitability", Harvard Business School Press. (1998).

21. Filson, A. and Rohrbacher, G.: Design Intercalated: The AtFAB Project, International Journal of Design Sciences and Technology, Vol.18 No. 2, ISSN 1630-7267 (2011).

22. Marsh P.: Production processes: A lightbulb moment. http://www.ft.com/cms/s/0/b59678b4-313b11e1-a62a-00144feabdc0.html\#axzz3XLUwvJwt, last retrieved 15/4/2015. 